\title{
Delayed resolution of syrinx after posterior fossa decompression without dural opening in children with Chiari malformation Type I
}

\author{
Benjamin C. Kennedy, MD, ${ }^{1}$ Taylor B. Nelp, BA, ${ }^{1}$ Kathleen M. Kelly, MD, ${ }^{1}$ Michelle Q. Phan, BS, ${ }^{1}$ \\ Samuel S. Bruce, MA, ${ }^{1}$ Michael M. McDowell, MD, ${ }^{2}$ Neil A. Feldstein, MD, ${ }^{1,3}$ and \\ Richard C. E. Anderson, MD1,3 \\ 'Department of Neurological Surgery and ${ }^{3}$ Children's Hospital of New York, Columbia University, New York, New York; and \\ 2Department of Neurological Surgery, University of Pittsburgh, Pennsylvania
}

\begin{abstract}
OBJECT Chiari malformation Type I (CM-I) is associated with a syrinx in $25 \%-85 \%$ of patients. Although posterior fossa decompression (PFD) without dural opening is an accepted treatment option for children with symptomatic CM-I, many surgeons prefer to open the dura if a syrinx exists. The purpose of this study was to investigate the frequency and timing of syrinx resolution in children undergoing PFD without dural opening for CM-I.

METHODS A retrospective review of 68 consecutive pediatric patients with $\mathrm{CM}-\mathrm{I}$ and syringomyelia who underwent PFD without dural opening was conducted. Patient demographics, presenting symptoms and signs, radiographic findings, and intraoperative ultrasound and neuromonitoring findings were studied as well as the patients' clinical and radiographic follow-up.

RESULTS During the mean radiographic follow-up period of 32 months, $70 \%$ of the syringes improved. Syrinx improvement occurred at a mean of 31 months postoperatively. All patients experienced symptom improvement within the 1st year, despite only $26 \%$ of patients showing radiographic improvement during that period. Patients presenting with sensory symptoms or motor weakness had a higher likelihood of having radiographic syrinx improvement postoperatively.

CONCLUSIONS In children with CM-I and a syrinx undergoing PFD without dural opening, syrinx resolution occurs in approximately $70 \%$ of patients. Radiographic improvement of the syrinx is delayed, but this does not correlate temporally with symptom improvement. Sensory symptoms or motor weakness on presentation are associated with syrinx resolution after surgery.

http://thejns.org/doi/abs/10.3171/2015.4.PEDS1572
\end{abstract}

KEY WORDS syrinx; syringomyelia; Chiari; nondural opening; suboccipital decompression; outcomes

$\mathrm{C}$ HIARI malformation Type I (CM-I) is associated with syrinx in $25 \%-85 \%$ of patients. $1,11,12,18,22,26,32$, The descent of the cerebellar tonsils through the foramen magnum in CM-I is associated with abnormal CSF dynamics at the craniocervical junction, and it has been posited that these effects play a role in syrinx formation. A syrinx is considered responsible for motor, sensory, and some pain symptoms as well as scoliosis. ${ }^{21,23,43,47}$
A syrinx associated with pediatric CM-I is considered by many surgeons an indication for surgical treatment, usually by posterior fossa decompression (PFD). ${ }^{4,11,25,26,32,35,42}$ PFD with dural opening has been associated with improvement in syrinx in $50 \%-100 \%$ of patients, with symptom resolution commonly occurring before syrinx improvement, and scoliosis improvement often occurring after syrinx improvement. . $^{1-8,10-12,15-17,20,26,27,29-35,42,44}$

A variety of methods for PFD have been described for

ABBREVIATIONS BAER = brainstem auditory evoked response; $\mathrm{CM}-\mathrm{I}=$ Chiari malformation Type I; PFD = posterior fossa decompression; SSEP = somatosensory evoked potential.

SUBMITTED February 2, 2015. ACCEPTED April 28, 2015.

INCLUDE WHEN CITING Published online August 28, 2015; DOI: 10.3171/2015.4.PEDS1572. 
pediatric CM-I with favorable outcomes. ${ }^{13,14,26,32}$ Although pediatric neurosurgeons have a great deal of experience with PFD with duraplasty, both case series as well as intraoperative electrophysiological studies have demonstrated that many patients can experience physiological decompression without opening of the dura. . $^{2,3,8,15,32,49}$ As a result, it is controversial whether the dura must be opened for adequate decompression.

Rapid syrinx improvement in these patients has been noted frequently with dural opening, ${ }^{1-8,10-12,15-17,20,26,27,29-35}$, ${ }^{42,44,46}$ and some pediatric neurosurgeons consider the presence of a syrinx to be an indication to open the dura in PFD. ${ }^{17,19,36,39}$ However, radiographic syrinx improvement has been shown to be unnecessary for symptom improvement, $, 6,8,15,26,37,46$ and a syrinx may resolve in delayed fashion. ${ }^{9}$ The time course of syrinx resolution after dural opening surgery in pediatric CM-I has been described recently, ${ }^{46}$ but no large series has addressed this after nondural opening surgery.

The purpose of this study was to determine the clinical outcomes as well as the frequency and time course of syrinx improvement after PFD without dural opening in children with CM-I and a syrinx.

\section{Methods}

Following approval by the Institutional Review Board at Columbia University Medical Center/Morgan Stanley Children's Hospital of NewYork-Presbyterian, a retrospective analysis was undertaken of all 68 patients with a syrinx of greater than $2 \mathrm{~mm}$ who were younger than 21 years and who underwent surgical decompression of CM-I without dural opening performed by the senior authors (N.A.F. and R.C.A.) between 2003 and 2013. Preoperative and postoperative records from office charts, operative reports, inpatient records, and pre- and postoperative images were reviewed. All patients had undergone preoperative MRI of the brain and spinal cord to evaluate the malformation and syrinx.

Patients were excluded from the study if they underwent a PFD with dural opening. We typically perform PFD without dural opening for children with CM-I regardless of whether there is a syrinx. PFD with dural opening was performed as the primary procedure if any of the following were present: 1) rapidly progressing neurological deficit, 2) rapidly progressing scoliosis with a syrinx and Cobb angle greater than $35^{\circ}$, and 3) tonsillar descent below the caudal aspect of the $\mathrm{C}-2$ lamina on preoperative MRI. Patients who underwent PFD without dural opening were excluded from analysis if they had previously undergone PFD at another institution or if it was believed they had acquired, rather than congenital, Chiari malformation secondary to spinal pathology or spine surgery. Patients with complex craniocervical junction anomalies who required posterior occipitocervical fusion at the time of the PFD were also excluded.

Each patient underwent a bony decompression of the craniocervical junction without opening of the dura as previously described. ${ }^{24}$ Briefly, under general anesthesia, the patient was placed in 3-point Mayfield fixation, and neurophysiological monitoring of somatosensory evoked potentials (SSEPs) and brainstem auditory evoked responses (BAERs) was performed with the patient supine and after prone positioning and fixation with neck flexion. SSEP monitoring was performed to ensure safety of positioning with neck flexion, ${ }^{2}$ while BAERs were monitored as a potential indicator of physiological decompression. ${ }^{3}$ After standard surgical preparation, draping, and administration of local anesthesia, an incision was made from the inion to the upper cervical region. Subperiosteal dissection was performed exposing the occiput, foramen magnum, and C-1, and a generous craniectomy was performed using a Midas drill and rongeurs. A C-1 laminectomy was routinely performed with rongeurs.

Intraoperative ultrasonography was used at this point to confirm that the dural exposure was adequate to reach the caudal aspect of the tonsils. In the rare case that the caudal aspect of the tonsils could not be appreciated above C-2 on ultrasonography, a partial laminectomy or undercutting was performed on the rostral aspect of C-2. No patient underwent complete $\mathrm{C}$-2 laminectomy.

The atlantooccipital ligament was then sharply incised and numerous rostrocaudal scoring incisions were made in the outer layer of the cervical dura (Fig. 1). Ultrasound was repeated to confirm improvement in movement of the cerebellar tonsils and an increase in the subarachnoid spaces dorsal and ventral to the cerebellar tonsils. Meticulous inspection for CSF leak as well as hemostasis were then performed prior to multilayer closure with absorbable sutures.

In general, patients underwent follow-up MRI 1 year postoperatively, unless earlier MRI was clinically indicated. Patients with large multiloculated syringes were more likely to be followed with yearly serial MR images (even if they were doing well clinically) until substantial radiographic improvement of the syrinx was seen.

Statistical analyses were performed using the Student t-test or Fisher's exact test, as appropriate.

\section{Results \\ Patients}

Sixty-eight consecutive patients undergoing PFD without dural opening for CM-I with an associated syrinx by the senior authors between 2003 and 2013 were identified. Forty-three percent (29/68) were boys, and the mean age was 10.9 years (range 3-20 years). Patients presented with a mean symptom duration of 1.9 years. Clinical outpatient follow-up was available for all patients, and the mean follow-up time was 40 months. Five patients had surgery within 1 year of data collection and were being clinically followed but had not yet undergone postoperative imaging, and 6 other patients did not have imaging available for review. Therefore, at least 1 postoperative MRI study was evaluated for the remaining 57 patients. The mean radiographic follow-up for these patients was 32 months.

\section{Presentation}

Subjective complaints of headache and neck pain were the most common presenting symptoms (Table 1). Taken together, headache, neck pain, and irritability of a younger patient were present in $62 \%(42 / 68)$ of patients at presenta- 


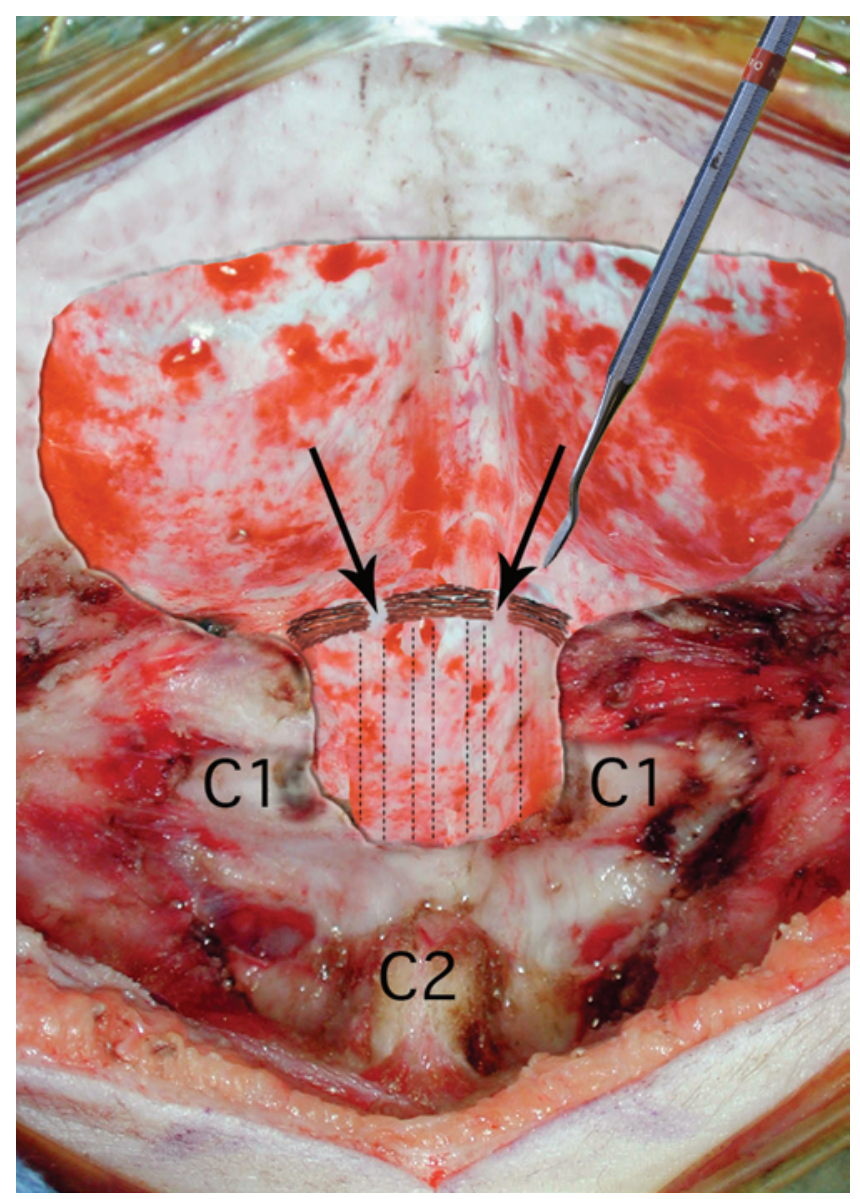

FIG. 1. Intraoperative photograph obtained after bony decompression, with overlaid illustration to indicate the general spatial orientation of the techniques of sectioning the atlantooccipital ligament (arrows) and the vertical scoring incisions in the outer layer of the dura (dashed lines), along with the instrument used for the vertical scoring incisions. Figure is available in color online only.

tion. Hyperreflexia and sensory symptoms were also common in this cohort. Twelve patients were asymptomatic except for a syrinx and CM-I. Mean tonsillar descent was $13.7 \mathrm{~mm}$ below the foramen magnum. Sixty-three percent $(43 / 68)$ of syringes spanned both cervical and thoracic segments, 9 of which $(13 \%)$ spanned the entire length of the spinal cord. Twenty-two percent (15/68) of syringes were isolated to the cervical region, and the remaining $15 \%(10 / 68)$ were isolated thoracic syringes. Twenty-five percent $(17 / 68)$ of patients presented with scoliosis with a Cobb angle of at least $10^{\circ}$. On presentation, 4 patients had mild to moderate ventriculomegaly, 1 had neurofibromatosis Type 1 , and 1 had a tethered cord.

\section{Intraoperative Findings}

All patients underwent intraoperative neuromonitoring with SSEPs and BAERs throughout the surgery, as well as intraoperative ultrasound after suboccipital craniectomy and C-1 laminectomy. No concerning electrophysiological changes were reported during any surgery. Eighty-four percent (57/68) of patients demonstrated improvement in the BAER I-V interpeak latency intraoperatively, and the
TABLE 1. Presenting symptoms and signs

\begin{tabular}{lc}
\hline \multicolumn{1}{c}{ Presenting Symptom/Sign } & No. of Patients \\
\hline Atypical headache & 24 \\
\hline Neck pain & 22 \\
\hline Occipital/tussive headache & 19 \\
\hline Hyperreflexia & 20 \\
\hline Sensory symptoms & 16 \\
\hline Dysphagia & 9 \\
\hline Back pain & 9 \\
\hline Motor weakness & 7 \\
\hline Ataxia & 7 \\
\hline Asymmetric abdominal reflexes & 7 \\
\hline Snoring & 6 \\
\hline Behavioral symptoms/developmental delay & 5 \\
\hline Irritability & 4 \\
\hline Nystagmus & 3 \\
\hline
\end{tabular}

remaining 11 patients had stable recordings; $8.8 \%(6 / 68)$ of patients underwent a partial superior C-2 laminectomy based on suboptimal decompression of the cerebellar tonsils seen on initial intraoperative ultrasound.

\section{Complications}

There were no major complications or deaths. Two patients experienced minor complications, one with a perioperative pneumonia and another with thigh paresthesias due to positioning.

\section{Clinical Outcome}

All $56(100 \%)$ of the patients presenting with Chiari symptoms experienced at least some degree of symptomatic improvement within the 1st postoperative year. All 12 (100\%) of the patients who had asymptomatic CM-I with syrinx demonstrated syrinx improvement. Eighty-eight percent $(60 / 68)$ of patients were asymptomatic or minimally symptomatic throughout the follow-up period. Forty-six percent $(31 / 68)$ were completely asymptomatic and $43 \%(29 / 68)$ remained with subtle, improved symptoms that did not affect their return to school or routine activities. Twelve percent $(8 / 68)$ of patients required reoperation with dural opening for progression of scoliosis without syrinx improvement or return of Chiari symptoms, 3 of whom demonstrated a concomitantly worsening syrinx. None of these patients were noted to have adhesions or webs obstructing outflow of the fourth ventricle.

\section{Syrinx Outcome}

The 57 patients with available images were studied with a mean radiographic follow-up of 32 months, and $70 \%$ (40) demonstrated radiographic improvement on MRI. Of these 40 improved syringes, one-third (13) demonstrated near complete collapse and an additional 20\% (8) were at least $50 \%$ smaller, with $47 \%$ (19) showing more modest improvement. All 12 asymptomatic syringes demonstrated radiographic improvement postoperatively.

Eighteen percent (3/17) of patients whose syringes did 
not improve required reoperation for persistent or worsening Chiari symptoms: 2 of these patients had demonstrated earlier radiographic syrinx improvement and 1 had remained stable. Despite radiographic improvement of the syrinx, $12 \%(5 / 40)$ of patients underwent a second operation for clinical symptom recurrence.

Age, duration of symptoms at presentation, degree of tonsillar ectopia, extent of cord syrinx, sensory or motor symptoms of the trunk or extremities, need to perform partial C-2 laminectomy based on intraoperative ultrasonography findings, and presence and degree of scoliosis were all assessed for a possible influence on syrinx resolution after PFD without dural opening. The association between motor/sensory symptoms and radiographic resolution of syrinx is determined by the difference between the proportion of patients with these symptoms whose syringes resolve (94\%) and the proportion of patients without these symptoms whose syringes resolve $(64 \%)(\mathrm{p}$ $=0.011)$. No other variables were associated with syrinx resolution (Table 2).

For the 17 patients with scoliosis, the median Cobb angle on presentation was $25^{\circ}$. Fourteen patients had appropriate follow-up imaging available for review. Nine patients had improvement of the syrinx and 5 did not. Of the 9 patients with an improving syrinx, 1 had improvement of scoliosis; 6 had stabilization of the Cobb angle (less than $10^{\circ}$ change), 1 of whom underwent spinal fusion surgery; 1 demonstrated progression of scoliosis and underwent spinal fusion surgery; and 1 demonstrated progression of scoliosis, underwent reoperation for dural opening PFD, continued to exhibit scoliosis progression, and then underwent spinal fusion surgery. Of the 5 patients whose syringes did not improve, 2 exhibited improving scoliosis; 1 patient's Cobb angle was stable; 1 demonstrated scoliosis progression and underwent spinal fusion surgery; and 1 demonstrated scoliosis progression, underwent reoperation for dural opening PFD, continued to exhibit scoliosis progression, and underwent spinal fusion surgery (Table 3 ).

\section{Timing of Syrinx Improvement}

For the 70\% (40/57) of patients who did demonstrate radiographic improvement, the median and mean time to improvement were 21 and 31 months, respectively. Syringes that were not seen to improve were followed radiographically for a mean of 33 months. Some patients, such as the patient in Fig. 2, improved symptomatically early in their postoperative course, but maintained a stable syrinx size for months or years prior to eventual radiographic resolution. Specifically, 19 syringes improved in the 1st postoperative year, 10 in the 2 nd year, 4 in the 3 rd year, 3
TABLE 3. Scoliosis outcomes by syrinx outcomes

\begin{tabular}{lccc}
\hline & \multicolumn{4}{c}{ No. of Patients } \\
\cline { 2 - 4 } \multicolumn{1}{c}{ Syrinx } & $\begin{array}{c}\text { Improved } \\
\text { Cobb Angle }\end{array}$ & $\begin{array}{c}\text { Stable Cobb } \\
\text { Angle* }\end{array}$ & $\begin{array}{c}\text { Worsened Cobb } \\
\text { Angle (also reop } \\
\text { for Chiari) }\end{array}$ \\
\hline Improving & 1 & 6 & $2(1)$ \\
\hline Stable or worsening & 2 & 1 & $2(1)$ \\
\hline * Stable Cobb angle was considered $<10^{\circ}$ of change from the preoperative \\
baseline.
\end{tabular}

in the 4th year, 1 in the 5 th year, 1 in the 6 th year, 1 in the 7th year, and 1 in the 8th year (Table 4, Fig. 3).

Five percent (3/57) of patients demonstrated worsening of the syrinx, and all 3 had concomitant recurrence of Chiari symptoms and required reoperation. Two of these 3 patients had experienced radiographic and symptomatic improvement at 1 and 19 months, respectively, followed by symptom recurrence and worsening of syrinx at 7 and 35 months, respectively.

\section{Discussion}

In this report, we have demonstrated that: 1) $70 \%$ of children undergoing PFD without dural opening for CM-I with syrinx will have radiographic improvement in the syrinx, 2) radiographic improvement of the syrinx occurs in a delayed fashion postoperatively, 3) syrinx improvement is not essential for clinical improvement, and 4) patients who present with motor/sensory symptoms are more likely to have syrinx improvement. To our knowledge, this is the largest reported series of outcomes after posterior fossa decompression without dural opening in children with CM-I with syrinx.

Previous studies have shown that CM-I induces alterations in CSF dynamics at the foramen magnum that can cause a syrinx in $25 \%-85 \%$ of patients. ${ }^{1,11,12,18,22,26,32,35,42}$ Children with CM-I have smaller posterior fossae than controls, ${ }^{28,38,41,45}$ and in 1 study, patients with an associated syrinx had yet smaller posterior fossae than CM-I patients without a syrinx. ${ }^{40}$ Syrinx has a strong association with scoliosis as well as motor and sensory symptoms. Many pediatric neurosurgeons consider a syrinx that is associated with CM-I an indication for PFD., 411,25,26,32,35,42 High rates of radiographic syrinx improvement have been reported after PFD with dural opening in pediatric CM-I, with symptom resolution often occurring prior to syrinx resolution and scoliosis improvement often occurring after. ${ }^{1-8,10-12,15-17,20,26,27,29-35,42,44}$ In part because syrinx improvement has been noted to occur in the majority of

TABLE 2. Patients whose syringes improved versus those whose syringes failed to improve

\begin{tabular}{lcccccccccc}
\hline \multicolumn{1}{c}{ Syrinx* } & $\begin{array}{c}\text { Total No. of } \\
\text { Patients }\end{array}$ & $\begin{array}{c}\text { Radiographic } \\
\text { Follow-Up } \\
(\mathrm{mos})\end{array}$ & $\begin{array}{c}\text { Age } \\
(\mathrm{yrs})\end{array}$ & $\begin{array}{c}\text { Symptom } \\
\text { Duration } \\
(\mathrm{yrs})\end{array}$ & $\begin{array}{c}\text { Tonsillar } \\
\text { Descent } \\
(\mathrm{mm})\end{array}$ & $\begin{array}{c}\text { No. w/ } \\
\text { Whole Cord } \\
\text { Syrinx }\end{array}$ & $\begin{array}{c}\text { No. w/ Motor } \\
\text { \&/or Sensory } \\
\text { Symptoms }\end{array}$ & $\begin{array}{c}\text { No. w/ C-2 } \\
\text { Laminectomy }\end{array}$ & $\begin{array}{c}\text { No. w/ } \\
\text { Scoliosis }\end{array}$ & $\begin{array}{c}\text { No. w/ Reoperation } \\
\text { Improving }\end{array}$ \\
\hline Stable/worsening & 17 & 31 & 10.4 & 2.3 & 13.5 & 6 & 16 & 3 & 9 \\
\hline p value & 33 & 11 & 1.7 & 15.8 & 3 & 1 & 2 & 5 \\
\hline
\end{tabular}

* Many presenting signs and symptoms not tabulated here exhibited similar proportions between groups and/or had low numbers of patients. 

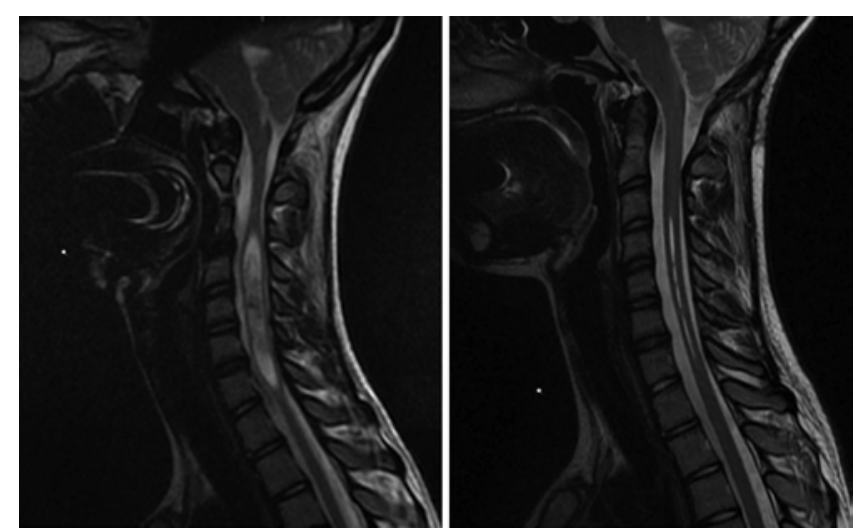

FIG. 2. Sagittal T2-weighted MR images obtained in a 15-year-old girl who presented with a 6 -month history of dizziness and episodes of visual loss with CM-I with $9 \mathrm{~mm}$ of tonsillar ectopia on MRI with an associated cervicothoracic syrinx. Left: Preoperative MRI showing CM-I and syrinx. Right: Image obtained 12 months after nondural opening posterior fossa decompression shows dramatic reduction of syrinx.

patients at an early time point (within a year) after dural opening, ${ }^{1-8,10-12,15-17,20,26,27,29-35,42,44,46}$ a large majority of pediatric neurosurgeons consider the presence of a syrinx to be an indication to open the dura during PFD. ${ }^{17,19,36,39} \mathrm{At}$ the 2006 American Society of Pediatric Neurosurgeons meeting, for example, a survey of $50 \%$ of the membership demonstrated that for children with a symptomatic CM-I and syrinx, only $4 \%$ would perform nondural opening surgery and another $4 \%$ would use ultrasound to guide whether to add duraplasty, with the vast majority opting for duraplasty with or without tonsillar resection. ${ }^{36}$

However, controversy exists over whether the dura must be opened for successful surgery for pediatric CM-I with or without a syrinx, with good clinical outcomes being reported for a variety of methods. ${ }^{13,14,26,32}$ Furthermore, several groups have reported symptom improvement after PFD in the absence of radiographic syrinx improvement, $6,8,15,26,37,46$ and it has been shown in some cases that the syrinx may resolve in a delayed fashion. ${ }^{9}$ The frequency and time course of syrinx resolution after PFD without dural opening has not been previously studied in a large series. This information is important for neurosurgeons when determining whether to perform a dural opening procedure and when deciding whether a prior PFD without dural opening has failed and further surgery is needed.

In the current series of children with CM-I and syrinx, $70 \%$ of patients undergoing PFD without dural opening had a radiographic improvement in the syrinx. This rate is similar to previous studies that have reported the proportion of syrinx improvement after PFD with dural opening between $55 \%$ and $100 \% .^{1-3,5,6,11,20,26,35,44}$ In the largest series of patients undergoing PFD with dural opening for pediatric CM-I, $80 \%$ radiographic syrinx improvement was reported. ${ }^{42}$ In the 2 largest series of patients with PFD and mixed dural opening and non-dural opening surgeries, the radiographic syrinx improvement rate was $62 \%$ in one study and $29 \%$ in the other, with no difference detected between the 2 procedure types. ${ }^{27,32}$ A recent meta-analysis that only included one of the aforementioned studies found that $56 \%$ of syringes improved after nondural open-
TABLE 4. Time from surgery to syrinx improvement

\begin{tabular}{cc}
\hline Postop $\mathrm{Yr}$ & No. of Patients \\
\hline 1 & 19 \\
\hline 2 & 10 \\
\hline 3 & 4 \\
\hline 4 & 3 \\
\hline 5 & 1 \\
\hline 6 & 1 \\
\hline 7 & 1 \\
\hline 8 & 1 \\
\hline
\end{tabular}

ing surgeries compared with $87 \%$ after dural opening, but due to the small number of patients in the literature with a syrinx who underwent PFD without dural opening, this difference was not statistically significant.

Among the patients who exhibited syrinx improvement, the median time to improvement was 21 months and the mean was 31 months, highlighting that some syringes will resolve several years after surgery. This is different from studies of the timing of syrinx resolution in series of dural opening surgery, which demonstrate more rapid radiographic change. One study by $\mathrm{Wu}$ and colleagues of 44 pediatric patients undergoing dural opening PFD for CM-I, syrinx, and scoliosis reported syrinx improvement in $82 \%$ of patients by 6 months postoperatively, and in $98 \%$ of patients over the course of follow-up. ${ }^{48}$ Wetjen and colleagues studied 29 adult patients with CM-I and syrinx after dural opening PFD and found the median time from surgery to greater than $50 \%$ reduction in syrinx size to be 3.6 months with a mean of 6.5 months. ${ }^{46}$ By 6 months, $86 \%$ of patients had demonstrated radiographic improvement, and all 29 patients demonstrated radiographic improvement during their follow-up. Furthermore, 59\% of patients in their series exhibited complete syrinx collapse. Taken together, these data suggest that in patients with CM-I and syrinx, dural opening surgery leads to a more rapid radiographic improvement of syrinx.

Importantly, our results and those of others suggest that syrinx resolution is not essential or directly related to clinical improvement. ${ }^{6,9,10,46}$ Despite only $70 \%$ of our patients showing radiographic improvement of the syrinx, $100 \%$ had initial improvement postoperatively and $88 \%$ remained asymptomatic or with minimal symptoms at last follow-up. These results are similar to the study by Wetjen et al., where at 6 months after PFD with dural opening, $96 \%$ of the patients experienced some degree of clinical improvement while only $86 \%$ had radiographic improvement of the syrinx; after 2 years, $68 \%$ remained mildly symptomatic even though $100 \%$ had radiographic improvement of the syrinx. In our study it is possible that with longer follow-up the number of patients with syrinx improvement will increase. This is supported by the fact that the mean time to syrinx resolution was 31 months and the mean follow-up was 33 months, with some patients demonstrating very late improvement up to the 8 th postoperative year (Table 4, Fig. 3).

In an attempt to identify preoperative factors that would indicate a higher likelihood of radiographic syrinx 


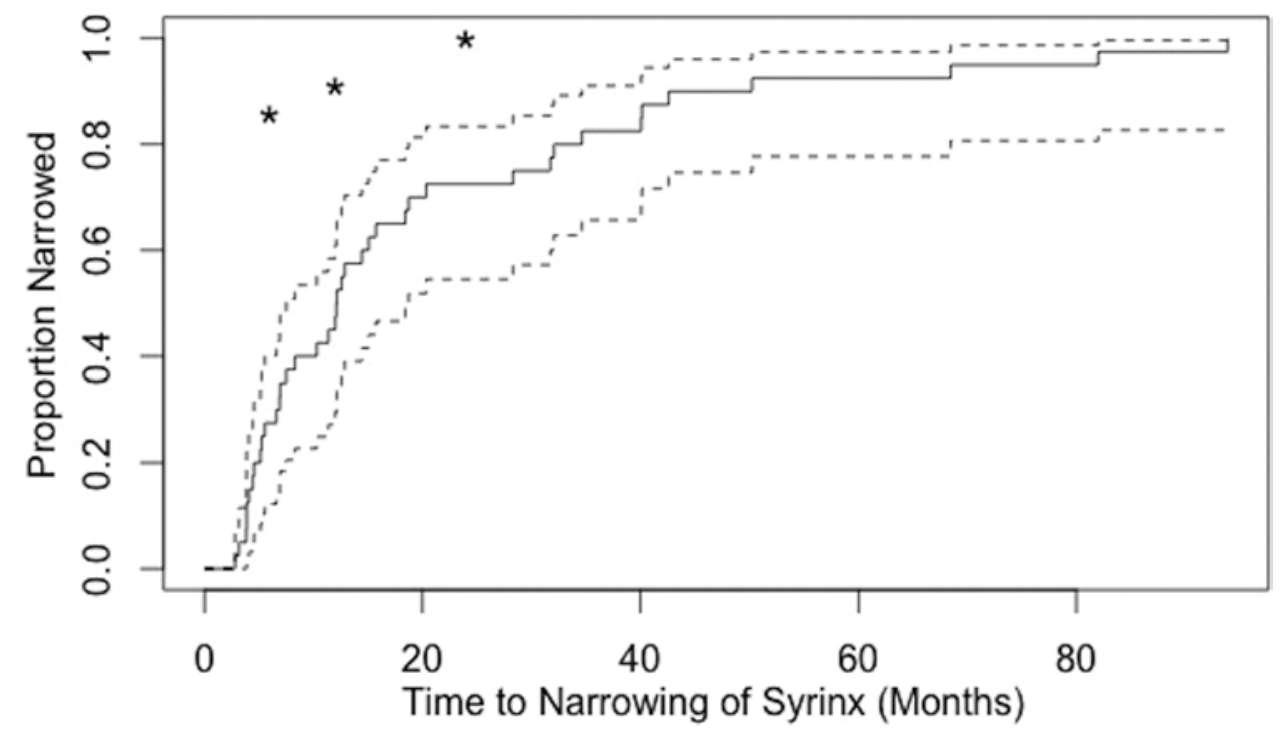

FIG. 3. Proportion of patients whose syringes had improved radiographically plotted against time after nondural opening surgery. Dashed lines indicate 95\% confidence intervals. The 3 asterisks indicate the proportion of patients with radiographic syrinx resolution at the 3 time points outlined in the Wetjen et al. ${ }^{46}$ study of dural opening surgeries for comparison.

improvement after PFD without dural opening, we performed multivariate regression analysis. Of all the factors studied, only the presence of preoperative motor or sensory symptoms was significantly associated with radiographic improvement of syrinx postoperatively $(\mathrm{p}=0.011)$. All 4 patients with mild to moderate ventriculomegaly experienced syrinx improvement.

Many surgeons routinely open the dura during PFD in patients with syringes to address possible arachnoid veils, webs, or adhesions obstructing outflow of the fourth ventricle that may contribute to syrinx formation. Although these pathological adhesions certainly exist in some patients, we believe that the frequency is very low because we did not see this in any of the 68 patients with syringes in this study. In the 8 patients in this series who underwent reoperation for recurrent symptoms with syrinx, no arachnoid veils, webs, or adhesions obstructing CSF flow were seen.

Our study is limited in its retrospective nature, and due to this, there are no strict criteria governing the timing of imaging for each patient, but we use a relatively consistent algorithm for postoperative imaging as described in Methods. The study is further limited by the lack of a control group and rather small numbers from a single center and a relatively short follow-up. However, the favorable clinical outcomes and radiographic improvement reported in this study suggest that the presence of a syrinx should not be considered a contraindication to PFD without dural opening. Furthermore, this study demonstrates that delayed improvement of syringomyelia after PFD without dural opening should be expected and is not an independent indication for reoperation. We look forward to future studies investigating similar questions that will have increased power and granularity generated from collaborative research networks including the Park-Reeves Syringomyelia Research Consortium.

\section{Conclusions}

In children with CM-I and a syrinx undergoing PFD without dural opening, syrinx resolution occurs in approximately $70 \%$ of patients. Radiographic improvement of the syrinx is delayed, but this does not correlate temporally with symptom improvement. Sensory symptoms or motor weakness on presentation are associated with syrinx resolution after surgery.

\section{References}

1. Alzate JC, Kothbauer KF, Jallo GI, Epstein FJ: Treatment of Chiari I malformation in patients with and without syringomyelia: a consecutive series of 66 cases. Neurosurg Focus 11(1):E3, 2001

2. Anderson RC, Dowling KC, Feldstein NA, Emerson RG: Chiari I malformation: potential role for intraoperative electrophysiologic monitoring. J Clin Neurophysiol 20:65-72, 2003

3. Anderson RC, Emerson RG, Dowling KC, Feldstein NA: Improvement in brainstem auditory evoked potentials after suboccipital decompression in patients with Chiari I malformations. J Neurosurg 98:459-464, 2003

4. Attenello FJ, McGirt MJ, Atiba A, Gathinji M, Datoo G, Weingart J, et al: Suboccipital decompression for Chiari malformation-associated scoliosis: risk factors and time course of deformity progression. J Neurosurg Pediatr 1:456-460, 2008

5. Attenello FJ, McGirt MJ, Garcés-Ambrossi GL, Chaichana KL, Carson B, Jallo GI: Suboccipital decompression for Chiari I malformation: outcome comparison of duraplasty with expanded polytetrafluoroethylene dural substitute versus pericranial autograft. Childs Nerv Syst 25:183-190, 2009

6. Attenello FJ, McGirt MJ, Gathinji M, Datoo G, Atiba A, Weingart $\mathrm{J}$, et al: Outcome of Chiari-associated syringomyelia after hindbrain decompression in children: analysis of 49 consecutive cases. Neurosurgery 62:1307-1313, 2008

7. Brockmeyer D, Gollogly S, Smith JT: Scoliosis associated with Chiari 1 malformations: the effect of suboccipital decompression on scoliosis curve progression: a preliminary study. Spine (Phila Pa 1976) 28:2505-2509, 2003 
8. Caldarelli M, Novegno F, Vassimi L, Romani R, Tamburrini G, Di Rocco C: The role of limited posterior fossa craniectomy in the surgical treatment of Chiari malformation Type I: experience with a pediatric series. J Neurosurg 106 (3 Suppl):187-195, 2007

9. Doughty KE, Tubbs RS, Webb D, Oakes WJ: Delayed resolution of Chiari I-associated hydromyelia after posterior fossa decompression: case report and review of the literature. Neurosurgery 55:711, 2004

10. Durham SR, Fjeld-Olenec K: Comparison of posterior fossa decompression with and without duraplasty for the surgical treatment of Chiari malformation Type I in pediatric patients: a meta-analysis. J Neurosurg Pediatr 2:42-49, 2008

11. Ellenbogen RG, Armonda RA, Shaw DW, Winn HR: Toward a rational treatment of Chiari I malformation and syringomyelia. Neurosurg Focus 8(3):E6, 2000

12. Eule JM, Erickson MA, O'Brien MF, Handler M: Chiari I malformation associated with syringomyelia and scoliosis: a twenty-year review of surgical and nonsurgical treatment in a pediatric population. Spine (Phila Pa 1976) 27:1451-1455, 2002

13. Fischer EG: Posterior fossa decompression for Chiari I deformity, including resection of the cerebellar tonsils. Childs Nerv Syst 11:625-629, 1995

14. Galarza M, Sood S, Ham S: Relevance of surgical strategies for the management of pediatric Chiari type I malformation. Childs Nerv Syst 23:691-696, 2007

15. Genitori L, Peretta P, Nurisso C, Macinante L, Mussa F: Chiari type I anomalies in children and adolescents: minimally invasive management in a series of 53 cases. Childs Nerv Syst 16:707-718, 2000

16. Ghanem IB, Londono C, Delalande O, Dubousset JF: Chiari I malformation associated with syringomyelia and scoliosis. Spine (Phila Pa 1976) 22:1313-1318, 1997

17. Hankinson T, Tubbs RS, Wellons JC: Duraplasty or not? An evidence-based review of the pediatric Chiari I malformation. Childs Nerv Syst 27:35-40, 2011

18. Hankinson TC, Klimo P Jr, Feldstein NA, Anderson RC, Brockmeyer D: Chiari malformations, syringohydromyelia and scoliosis. Neurosurg Clin N Am 18:549-568, 2007

19. Haroun RI, Guarnieri M, Meadow JJ, Kraut M, Carson BS: Current opinions for the treatment of syringomyelia and Chiari malformations: survey of the Pediatric Section of the American Association of Neurological Surgeons. Pediatr Neurosurg 33:311-317, 2000

20. Hoffman CE, Souweidane MM: Cerebrospinal fluid-related complications with autologous duraplasty and arachnoid sparing in type I Chiari malformation. Neurosurgery 62 (3 Suppl 1):156-161, 2008

21. Huebert HT, MacKinnon WB: Syringomyelia and scoliosis. J Bone Joint Surg Br 51:338-343, 1969

22. Hwang SW, Samdani AF, Jea A, Raval A, Gaughan JP, Betz RR, et al: Outcomes of Chiari I-associated scoliosis after intervention: a meta-analysis of the pediatric literature. Childs Nerv Syst 28:1213-1219, 2012

23. Isu T, Chono Y, Iwasaki Y, Koyanagi I, Akino M, Abe H, et al: Scoliosis associated with syringomyelia presenting in children. Childs Nerv Syst 8:97-100, 1992

24. Kennedy BC, Kelly KMPM, Phan MQ, Bruce SS, McDowell MM, Anderson RC, et al: Outcomes after suboccipital decompression without dural opening in children with Chiari malformation Type I. J Neurosurg Pediatr [epub ahead of print May 1, 2015. DOI: 10.3171/2014.12.PEDS14487]

25. Kontio K, Davidson D, Letts M: Management of scoliosis and syringomyelia in children. J Pediatr Orthop 22:771-779, 2002

26. Krieger MD, McComb JG, Levy ML: Toward a simpler surgical management of Chiari I malformation in a pediatric population. Pediatr Neurosurg 30:113-121, 1999
27. McGirt MJ, Attenello FJ, Atiba A, Garces-Ambrossi G, Datoo G, Weingart JD, et al: Symptom recurrence after suboccipital decompression for pediatric Chiari I malformation: analysis of 256 consecutive cases. Childs Nerv Syst 24:1333-1339, 2008

28. Milhorat TH, Chou MW, Trinidad EM, Kula RW, Mandell M, Wolpert C, et al: Chiari I malformation redefined: clinical and radiographic findings for 364 symptomatic patients. Neurosurgery 44:1005-1017, 1999

29. Munshi I, Frim D, Stine-Reyes R, Weir BK, Hekmatpanah J, Brown F: Effects of posterior fossa decompression with and without duraplasty on Chiari malformation-associated hydromyelia. Neurosurgery 46:1384-1390, 2000

30. Mutchnick IS, Janjua RM, Moeller K, Moriarty TM: Decompression of Chiari malformation with and without duraplasty: morbidity versus recurrence. J Neurosurg Pediatr 5:474478, 2010

31. Nagib MG: An approach to symptomatic children (ages 4-14 years) with Chiari type I malformation. Pediatr Neurosurg 21:31-35, 1994

32. Navarro R, Olavarria G, Seshadri R, Gonzales-Portillo G, McLone DG, Tomita T: Surgical results of posterior fossa decompression for patients with Chiari I malformation. Childs Nerv Syst 20:349-356, 2004

33. Ozerdemoglu RA, Denis F, Transfeldt EE: Scoliosis associated with syringomyelia: clinical and radiologic correlation. Spine (Phila Pa 1976) 28:1410-1417, 2003

34. Ozerdemoglu RA, Transfeldt EE, Denis F: Value of treating primary causes of syrinx in scoliosis associated with syringomyelia. Spine (Phila Pa 1976) 28:806-814, 2003

35. Park JK, Gleason PL, Madsen JR, Goumnerova LC, Scott RM: Presentation and management of Chiari I malformation in children. Pediatr Neurosurg 26:190-196, 1997

36. Rocque BG, George TM, Kestle J, Iskandar BJ: Treatment practices for Chiari malformation type I with syringomyelia: results of a survey of the American Society of Pediatric Neurosurgeons. J Neurosurg Pediatr 8:430-437, 2011

37. Sakamoto H, Nishikawa M, Hakuba A, Yasui T, Kitano S, Nakanishi N, et al: Expansive suboccipital cranioplasty for the treatment of syringomyelia associated with Chiari malformation. Acta Neurochir (Wien) 141:949-961, 1999

38. Schady W, Metcalfe RA, Butler P: The incidence of craniocervical bony anomalies in the adult Chiari malformation. $\mathbf{J}$ Neurol Sci 82:193-203, 1987

39. Schijman E, Steinbok P: International survey on the management of Chiari I malformation and syringomyelia. Childs Nerv Syst 20:341-348, 2004

40. Sgouros S, Kountouri M, Natarajan K: Posterior fossa volume in children with Chiari malformation Type I. J Neurosurg 105 (2 Suppl):101-106, 2006

41. Trigylidas T, Baronia B, Vassilyadi M, Ventureyra EC: Posterior fossa dimension and volume estimates in pediatric patients with Chiari I malformations. Childs Nerv Syst 24:329-336, 2008

42. Tubbs RS, Beckman J, Naftel RP, Chern JJ, Wellons JC III, Rozzelle CJ, et al: Institutional experience with 500 cases of surgically treated pediatric Chiari malformation Type I. J Neurosurg Pediatr 7:248-256, 2011

43. Tubbs RS, Doyle S, Conklin M, Oakes WJ: Scoliosis in a child with Chiari I malformation and the absence of syringomyelia: case report and a review of the literature. Childs Nerv Syst 22:1351-1354, 2006

44. Valentini L, Visintini S, Saletti V, Chiapparini L, Estienne M, Solero CL: Treatment for Chiari 1 malformation (CIM): analysis of a pediatric surgical series. Neurol Sci 32 (Suppl 3):S321-S324, 2011

45. Vega A, Quintana F, Berciano J: Basichondrocranium anomalies in adult Chiari type I malformation: a morphometric study. J Neurol Sci 99:137-145, 1990 
46. Wetjen NM, Heiss JD, Oldfield EH: Time course of syringomyelia resolution following decompression of Chiari malformation Type I. J Neurosurg Pediatr 1:118-123, 2008

47. Williams B: Orthopaedic features in the presentation of syringomyelia. J Bone Joint Surg Br 61-B:314-323, 1979

48. Wu T, Zhu Z, Jiang J, Zheng X, Sun X, Qian B, et al: Syrinx resolution after posterior fossa decompression in patients with scoliosis secondary to Chiari malformation type I. Eur Spine J 21:1143-1150, 2012

49. Zamel K, Galloway G, Kosnik EJ, Raslan M, Adeli A: Intraoperative neurophysiologic monitoring in 80 patients with Chiari I malformation: role of duraplasty. J Clin Neurophysiol 26:70-75, 2009

\section{Disclosure}

The authors report no conflict of interest concerning the materials or methods used in this study or the findings specified in this paper.

\section{Author Contributions}

Conception and design: Kennedy, Feldstein, Anderson. Acquisition of data: Kennedy, Nelp, Kelly, Phan, McDowell, Feldstein, Anderson. Analysis and interpretation of data: Kennedy, Nelp, Kelly, Phan, Bruce, Feldstein, Anderson. Drafting the article: Kennedy, Feldstein, Anderson. Critically revising the article: Kennedy, Anderson. Reviewed submitted version of manuscript: all authors. Approved the final version of the manuscript on behalf of all authors: Kennedy. Statistical analysis: Bruce. Administrative/technical/material support: Feldstein, Anderson . Study supervision: Kennedy, Feldstein, Anderson.

\section{Supplemental Information}

\section{Previous Presentation}

The current work has been accepted for presentation to the Congress of Neurological Surgeons Annual Meeting 2015.

\section{Correspondence}

Benjamin C. Kennedy, The Neurological Institute, 710 W. 168th St., 4th Fl., New York, NY 10032.email: benjamin.c.kennedy@ gmail.com. 